\title{
On the Relationship of Socio-Economic Status and Risk Factors for Alcoholic Liver Disease in North China
}

\author{
Haixia Wang ${ }^{1}$, Qiling Yin ${ }^{2}$, Xiaowei Zhang ${ }^{2}$ \& Cuiqin Zhang ${ }^{2}$ \\ ${ }^{1}$ Hospital of Qingdao University of Science and Technology, Qingdao, China \\ ${ }^{2}$ The Affiliated Hospital of Taishan Medical University, Tai'an, China \\ Correspondence: Haixia Wang, Hospital of Qingdao University of Science and Technology, QingDao 266061, \\ Shandong Province, China. Tel: 86-532-8895-6612
}

\author{
Received: February 1, 2018 Accepted: February 20, 2018 Online Published: February 28, 2018 \\ doi:10.5539/gjhs.v10n4p35 URL: https://doi.org/10.5539/gjhs.v10n4p35
}

\begin{abstract}
Background: The present article analyses the association between socioeconomic status (includes education, occupation, income and marriage) and alcoholic liver disease (ALD) risk factors (age, gender, obesity, quantity and duration of alcohol intake, alcoholic beverages, drinking patterns) in Taishan area of Shandong province, to provide scientific basis for the prevention of alcoholic liver disease for the people who mostly need it in north China.

Methods: Across-sectional survey of over 18--year-old inhabitants in Shandong Province in 2011 used multistage, randomized clustered sampling to identify 8186 subjects; $7295(89.12 \%)$ of them were interviewed. Questionnaires, designed by co-working of epidemiologists and hepatologists, included demographic characteristics, current medication use, medical history and health-relevant behaviors, i.e. alcohol consumption, dietary habits and physical activities. Anthropometric measurements, biochemical tests and abdominal ultrasonography were carried out. The sample was determined by Chi-square test, covariance analysis and logistic regression analysis.

Results: Because of the small number of female drinkers, alcoholic liver disease prevalence of female was obviously lower than that of male, the very study of the male drinkers is more meaningful and can be represent the whole drinkers group to some extent. Among the four socio-economic status (SES) indicators the marriage status seemed to be the most influential factor. People (men or women) without spouse had higher risk of alcoholic liver disease risk factors than those who had spouse. The risk of people who have different occupation is different. The higher education was associated with risk of ALD.

Conclusion: Marriage status seemed to be the most important measure of the socioeconomic indicators in relation to the alcoholic liver disease risk factors in the study of population. There is obvious relation between occupation status and alcoholic liver disease risk factors in men. The lower occupation had higher alcoholic liver disease risk factors. People with higher income and education had higher levels of drinking risk factors and lower level of obesity risk factors.
\end{abstract}

Keywords: alcohol drinking, liver diseases, prevalence, epidemiology, socio-economic status, risk factors

\section{Introduction}

Alcohol abuse and alcohol-induced liver disease (ALD) are a major public health problem in the worldwide (Rasineni et al., 2012; Moghe et al., 2011; Massey \& Arteel, 2012; Rehm, 2011). In 2013 U.S. media reported (Neild, 2013) that China has become the second country of drinking consumption only to the UK in the world. Based on the World Health Organization of Statistics data, from 1961 to 2005 the annual per capita consumption of alcoholic beverages in China increased 21.7-fold (from 0.49 liters to 10.61 liters, over 15 years old) (WHO, 2007, 2011). The development of ALD, except for some necessary conditions, but also closely related with genetic factors and environmental factors. It's generally believed that quantity and duration of alcohol intake, alcoholic beverages, drinking patterns, sex, race, obesity, genetic factors, nutrition, hepatitis virus infection is concerned (Fatty Liver and Alcoholic Liver Disease Study Group of the Chinese Liver Disease Association, 2010). In recent years, some epidemiological studies concerning ALD have been reported in China (Li et al., 2003; Lu et al., 2003; Yan et al., 2007; Huang et al., 2005; Fan et al., 2005; Sun, 2008; Zhou et al., 2007). Previously reported risk factors of current ALD in China included male gender middle age, daily alcohol intake, duration of drinking and 
obese (Li et al., 2003; Huang et al., 2005; Fan et al., 2005; Sun, 2008). There have been only a few studies reporting the association between ALD and sociodemographic characteristics other than age and gender. In xi'an survey, the ALD prevalence is $2.2 \%$ (female $0.3 \%$ ), the prevalence of ALD in urban is higher than in rural areas (Lu et al., 2003). Five years later, the survey in Shanxi-Gansu, prevalence of ALD was 3.87\% (male 4.98\%, female $1.47 \%$ ). The drinkers with middle and high-income or have family members who drink suffered more risks of ALD, and in terms of occupation, drinkers in authority suffered risks of fatty liver disease most, scientific and technical personnel suffered the lowest. In terms of age male from 40-year-old to 50-year-old reached the peak and female aged from 50 to 59 reached a peak Yan et al., 2007). In summary, prior studies in China have not considered a range of sociodemographic variables (e.g., age, marital status, and income) that have been shown to be associated with ALD in other countries (Jepsen et al., 2009), nor have they reflect the population-based data in small and medium -sized cities. Until the end of 2011, the population of small and medium -sized cities is 10.16 million and accounting for $75.4 \%$ of the country's total population. (Urban Economic Society of China Small and Medium-sized City's Economic Development Commission, 2012). Tai'an which is in the north of Taishan and in the south of Qufu in Shandong Province is the birthplace of Confucian culture (mainly Han nationality people). Taishan District with a population of about 760,100 can be considered as the representatives of small and medium-sized cities (the National Bureau of Statistics, 2011), so the survey results are representative.

Given the rapid social and economic changes in China, up-to-date epidemiological data on the socio-demographic pattern of ALD are needed. In this study, we investigated the association between socioeconomic status (includes education, occupation, income, current marriage status) is associated with ALD risk factors (drinking age, alcohol consumption, gender, obesity and the relationship between hepatitis B virus infection) in Tai'an city of Shandong province in china to provide scientific basis for the prevention of alcoholic liver disease for the people who mostly need it in China.

\section{Materials and Methods}

\subsection{Sampling}

The survey was carried out from September to November 2011. The primary sampling sites was Tai'an city in Shandong province in northern China. Multi-stage randomized cluster sampling methods were used to identity subjects. In the first stage, 15 neighborhood communities were randomly selected. Then 8186 households were randomly selected from the 15 neighborhood communities. 8186 could not be located (after 3 visits to the household). 170(2.08\%) refused, 721(8.80\%) only finished part of the interview and 7295(89.12\%) completed the interview. All respondents were individuals aged over 18 years older. All of the respondents gave written informed consent and the study protocol was proved by the Ethics committee of Taishan Medical University completion of the questionnaires was also voluntary.

\subsection{Diagnostic Criteria}

The diagnosis of ALD was confirmed according to the published data (Wang et al., 2014).

\subsection{Statistical Analysis}

Statistical analysis was performed with SPSS 17.0 for windows.The differences in categorical variables were tested by the Chi-square test $\left(\chi^{2}\right.$ test. Adjusted odds ratios and $95 \%$ confidential intervals derived from multiple logistic regression models were used to assess the relationship between ALD and socio-demographic variables. Two tailed values were considered to be significant at $<0.05$.

\section{Results}

\subsection{Demographic Characteristics of Alcoholic Liver Disease}

Among 7295 interviewees 3084 drink which accounted for 42.28\%, among 3629 male population 2704 drink, accounting for $87.68 \%$ of the total number of drinkers, male drinking rate was $74.51 \%$; among 3666 female population 415 drink accounting for $13.46 \%$ of the total number of drinkers, drinking rate was $11.32 \%$.

Among 7295 interviewees the number of ALD is 624 people, accounting for $8.55 \%$ of the total interviewees, among 3629 male population the number of ALD is 572 , accounting for $91.67 \%$ of the total number of ALD, male ALD prevalence rate is $15.76 \%$; among 3666 female population the number of ALD is 52 accounting for the $8.33 \%$ of the total number of ALD, the female ALD prevalence rate is $1.42 \%$.

ALD prevalence rate is $8.55 \%$ in the physical examination the general population, the prevalence rate was $20.23 \%$ in 3084 drinkers. Male ALD prevalence is $21.15 \%$ of male drinkers, female ALD prevalence rate accounted for $12.53 \%$ of the population of drinking women, analysis and comparison of ALD prevalence of people of all ages, with increasing age, the prevalence of ALD gradually increase, the highest in the 40-49 phase of the interviewees, 
a prevalence rate of $19.32 \%$ in the medical groups.

ALD population age distribution showed that in the male population, the number of 40 -year-old to 49 -year-old is the largest, this result is consistent with prior study in China (Cooperative Group of Alcoholic Liver Disease, 2007). In the female population, the number of aged 50 to 59 is the largest. In the survey population, the prevalence of ALD in turn 40-49 19.32\%, 50-59 8.36\%, > 60 8.24\%, 30-39 4.16\%, 18-29 1.13\%.

Table 1. Socio-Demographic Characteristics and Sex-specific Prevalence of Alcoholic Liver Disease

\begin{tabular}{|c|c|c|c|c|c|c|}
\hline & \multicolumn{2}{|c|}{ Total (7295) } & \multicolumn{2}{|c|}{ Male (3629) } & \multicolumn{2}{|c|}{ Female $(n=3666)$} \\
\hline & $\mathrm{N}$ & $\mathrm{n}(\%)$ & $\mathrm{N}$ & $\mathrm{n}(\%)$ & $\mathrm{N}$ & $\mathrm{n}(\%)$ \\
\hline \multicolumn{7}{|l|}{ Age, in years } \\
\hline $18-29$ & 1144 & $13(1.13)$ & 494 & $13(2.63)$ & 650 & $0(0.00)$ \\
\hline $30-39$ & 1872 & $78(4.16)$ & 806 & $78(9.68)$ & 1066 & $0(0.00)$ \\
\hline $40-49$ & 1615 & $312(19.32)$ & 874 & $286(32.72)$ & 741 & $26(3.51)$ \\
\hline $50-59$ & 1555 & $130(8.36)$ & 944 & $104(11.02)$ & 611 & $26(4.26)$ \\
\hline $60-$ & 1104 & $91(8.24)$ & 511 & $91(17.81)$ & 598 & $0(0.00)$ \\
\hline \multicolumn{7}{|c|}{ Years of education } \\
\hline$<7$ & 2321 & $338(14.56)$ & 1242 & $312(25.12)$ & 1079 & $26(2.41)$ \\
\hline $7-9$ & 2184 & $91(4.17)$ & 1040 & $91(8.75)$ & 1144 & $0(0.00)$ \\
\hline$>9$ & 2790 & $195(6.99)$ & 1347 & $169(12.55)$ & 1443 & $26(1.80)$ \\
\hline \multicolumn{7}{|c|}{ Mean monthly per capia family income, RMB } \\
\hline $0-$ & 2622 & $312(11.90)$ & 1257 & $260(20.68)$ & 1365 & $52(3.81)$ \\
\hline $800-$ & 2211 & $130(5.88)$ & 1171 & $130(11.10)$ & 1040 & $0(0.00)$ \\
\hline $1600-$ & 2462 & $182(7.39)$ & 1201 & $182(15.15)$ & 1261 & $0(0.00)$ \\
\hline \multicolumn{7}{|l|}{ Occupation } \\
\hline unemployed & 1087 & $13(1.20)$ & 489 & $13(2.66)$ & 598 & $0(0.00)$ \\
\hline blue collar & 4242 & $403(9.50)$ & 2344 & $377(16.08)$ & 1898 & $26(1.37)$ \\
\hline white collar & 1966 & $208(10.58)$ & 796 & $182(22.86)$ & 1170 & $26(2.22)$ \\
\hline \multicolumn{7}{|c|}{ Marital status } \\
\hline married & 5122 & $429(8.38)$ & 2522 & $403(15.98)$ & 2600 & $26(1.00)$ \\
\hline unmarried & 2173 & $195(8.97)$ & 1107 & $169(15.27)$ & 1066 & $26(2.44)$ \\
\hline Total & 7295 & $624(8.55)$ & 3629 & $572(15.76)$ & 3666 & $52(1.42)$ \\
\hline
\end{tabular}

\section{The distribution of alcoholic liver disease risk factors situation}

Men have higher levels of risk factors for ALD such as obesity, abdominal obesity, daily alcohol intake, duration of drinking and HBV infection than women (Table 2) 
Table 2. Sex-specific distribution of ALD risk factors

\begin{tabular}{|c|c|c|c|c|c|c|c|c|c|c|}
\hline \multirow{2}{*}{ Predictors } & \multicolumn{2}{|c|}{ Abdominal obesity } & \multicolumn{2}{|c|}{ Obesity } & \multirow{2}{*}{$\begin{array}{l}\text { Daily } \\
\text { intake }\end{array}$} & \multirow{2}{*}{$\begin{array}{l}\text { Alcohol } \\
\text { female }\end{array}$} & \multicolumn{2}{|c|}{$\begin{array}{l}\text { Duration } \\
\text { drinking }\end{array}$} & \multicolumn{2}{|c|}{ HBV infection } \\
\hline & male & female & male & female & & & male & female & male & female \\
\hline \multicolumn{11}{|l|}{ Age, in years } \\
\hline $18-29$ & $31.6^{\mathrm{a}}$ & 0 & $37.4^{\mathrm{a}}$ & 0 & $10.5^{\mathrm{a}}$ & 0 & $47.4^{\mathrm{a}}$ & 4 & $7.9^{\mathrm{a}}$ & 12 \\
\hline $30-39$ & $45.2^{\mathrm{a}}$ & 7.3 & $43.6^{\mathrm{a}}$ & 22 & $17.7^{\mathrm{a}}$ & 4.9 & $83.9^{\mathrm{a}}$ & 14.6 & $8.1^{\mathrm{a}}$ & 2.4 \\
\hline $40-49$ & $38.4^{\mathrm{a}}$ & 17.5 & 43.1 & 38.6 & $43.2^{\mathrm{a}}$ & 3.5 & $87.5^{\mathrm{a}}$ & 22.8 & 4.5 & 0 \\
\hline $50-59$ & $25.4^{\mathrm{a}}$ & 6.4 & $41.9^{\mathrm{a}}$ & 19.1 & $11^{\mathrm{a}}$ & 4.3 & $66.1^{\mathrm{a}}$ & 10.6 & $4.2^{\mathrm{a}}$ & 0 \\
\hline $60-$ & 29.5 & 30.4 & 34.2 & 39.1 & $28.3^{\mathrm{a}}$ & 0 & $47.9^{\mathrm{a}}$ & 4.5 & $5.5^{\mathrm{a}}$ & 4.8 \\
\hline \multicolumn{11}{|c|}{ Years of education } \\
\hline$<7$ & $27.6^{\mathrm{a}}$ & 19.3 & $38.2^{\mathrm{a}}$ & 43.4 & $35.7^{\mathrm{a}}$ & 4.8 & $75.2^{\mathrm{a}}$ & 7.2 & 8.4 & 0 \\
\hline $7-9$ & $38.4^{\mathrm{a}}$ & 12.5 & $51.3^{\mathrm{a}}$ & 12.5 & $10^{\mathrm{a}}$ & 2.3 & $61.3^{\mathrm{a}}$ & 11.4 & $5.3^{\mathrm{a}}$ & 7.2 \\
\hline$>9$ & $37.5^{\mathrm{a}}$ & 5.4 & $35.5^{\mathrm{a}}$ & 22.9 & $18.4^{\mathrm{a}}$ & 1.8 & $72.2^{\mathrm{a}}$ & 16.2 & $7.6^{\mathrm{a}}$ & 0 \\
\hline \multicolumn{11}{|c|}{ Mean monthly per capia family income, RMB } \\
\hline $0-$ & $29.6^{\mathrm{a}}$ & 7.6 & $42.3^{\mathrm{a}}$ & 25 & $28^{\mathrm{a}}$ & 5.7 & $76.7^{\mathrm{a}}$ & 11.4 & $7.3^{\mathrm{a}}$ & 3.8 \\
\hline $800-$ & $33.9^{\mathrm{a}}$ & 12.5 & $45.3^{\mathrm{a}}$ & 23.7 & $16.7^{\mathrm{a}}$ & 2.5 & $63.4^{\mathrm{a}}$ & 10 & $4.5^{\mathrm{a}}$ & 2.5 \\
\hline $1600-$ & $39.8^{\mathrm{a}}$ & 15.5 & $35.3^{\mathrm{a}}$ & 13 & $20.7^{\mathrm{a}}$ & 0 & $69.8^{\mathrm{a}}$ & 14.4 & 5.5 & 6.2 \\
\hline \multicolumn{11}{|l|}{ Occupation } \\
\hline unemployed & 17.2 & 19.6 & $17^{\mathrm{a}}$ & 23.9 & $5.5^{\mathrm{a}}$ & 0 & $33.3^{\mathrm{a}}$ & 0 & $2.9^{\mathrm{a}}$ & 0 \\
\hline blue collar & $37.2^{\mathrm{a}}$ & 11 & $46.3^{\mathrm{a}}$ & 24.7 & $22.3^{\mathrm{a}}$ & 2.7 & $72.1^{\mathrm{a}}$ & 9.6 & $6.1^{\mathrm{a}}$ & 2.7 \\
\hline white collar & $36.4^{\mathrm{a}}$ & 8.9 & $39.9^{\mathrm{a}}$ & 22.2 & $31^{\mathrm{a}}$ & 4.4 & $86.7^{\mathrm{a}}$ & 22.2 & 6.7 & 8.9 \\
\hline \multicolumn{11}{|l|}{ Marital status } \\
\hline married & $38.9^{\mathrm{a}}$ & 12.5 & $45.4^{\mathrm{a}}$ & 28.5 & $22.2^{\mathrm{a}}$ & 3 & $78.4^{\mathrm{a}}$ & 15 & $7.8^{\mathrm{a}}$ & 4 \\
\hline unmarried & $24^{\mathrm{a}}$ & 9.8 & $30.9^{\mathrm{a}}$ & 12.2 & $21.3^{\mathrm{a}}$ & 2.4 & $51.3^{\mathrm{a}}$ & 4.9 & 1.3 & 4.9 \\
\hline
\end{tabular}

${ }^{\mathrm{a} O d d s}$ ratio is significant, $\mathrm{p}<0.05$.

\section{Adjusted odds ratios, and 95\% confidence intervals (CI) of ALD risk factors by sociodemographic characteristics}

1). Abdominal obesity

After adjusting for age and other factors of the SES, the factors of age, income, occupation, marital and education are of impact on abdominal obesity in the overall population. The increasing age, higher income and occupation increase the risk of suffering from abdominal obesity, the lower education increases the risk of abdominal obesity and the single are more likely to suffer from abdominal obesity. (Table 3)

Table 3. Odds ratios of abdominal obesity adjusted for all socio-demographic characteristics in the overall population

\begin{tabular}{llllllll}
\hline & $\mathrm{B}$ & $\mathrm{S} . \mathrm{E}$, & Wals & df & Sig. & OR & OR95\%CI \\
\hline Age & -0.16 & 0.025 & 40.994 & 1 & 0.005 & 1.139 & $1.041-1.246$ \\
Income & 0.336 & 0.037 & 80.539 & 1 & 0.000 & 1.745 & $1.61-1.89$ \\
Occupation & -0.275 & 0.056 & 24.511 & 1 & 0.000 & 1.439 & $1.265-1.636$ \\
Marriage & -0.517 & 0.073 & 49.731 & 1 & 0.000 & 0.503 & $0.423-0.597$ \\
Education & -0.161 & 0.039 & 16.655 & 1 & 0.000 & 0.76 & $0.696-0.829$ \\
Constant & -0.427 & 0.177 & 5.814 & 1 & 0.000 & 0.111 & \\
\hline
\end{tabular}


After adjusting for age and other factors of the SES, occupation, marital status and education are of statistical impact in the male population and the occupational rank increase the risk, the higher level of education and income increase the risk of abdominal obesity and the male single is more likely to suffer abdominal obesity. (Table 4)

Table 4. Odds ratios of abdominal obesity adjusted for all socio-demographic characteristics in the male population

\begin{tabular}{llllllll}
\hline & $\mathrm{B}$ & S.E, & Wals & df & Sig. & OR & OR95\%CI \\
\hline age & 0.111 & 0.031 & 13.088 & 1 & 0.000 & 1.118 & $1.052-1.187$ \\
income & 0.197 & 0.044 & 19.516 & 1 & 0.000 & 1.217 & $1.116-1.328$ \\
occupation & -0.029 & 0.070 & 0.165 & 1 & 0.685 & 0.972 & $0.847-1.116$ \\
marriage & -0.690 & 0.089 & 59.600 & 1 & 0.000 & 0.501 & $0.421-0.597$ \\
education & 0.107 & 0.046 & 5.446 & 1 & 0.020 & 1.113 & $1.017-1.218$ \\
constant & -0.834 & 0.226 & 13.631 & 1 & 0.000 & 0.434 & \\
\hline
\end{tabular}

After adjusting for age and other factors of the SES, occupation, marital status and education are of statistical impact in the female population and the lower education and higher income increase the risk of abdominal obesity and the female single is more likely to suffer abdominal obesity. (Table 5)

Table 5. Odds ratios of abdominal obesity adjusted for all socio-demographic characteristics in the female population

\begin{tabular}{llllllll}
\hline & $\mathrm{B}$ & $\mathrm{S} . \mathrm{E}$, & Wals & $\mathrm{df}$ & Sig. & OR & OR95\%CI \\
\hline Age & -0.594 & 0.054 & 123.000 & 1 & 0.000 & 0.552 & $0.497-0.613$ \\
Income & 1.011 & 0.086 & 138.245 & 1 & 0.000 & 2.748 & $2.322-3.252$ \\
Occupation & -0.106 & 0.111 & 0.909 & 1 & 0.340 & 0.900 & $0.724-1.118$ \\
Marriage & -0.164 & 0.150 & 1.197 & 1 & 0.274 & 0.849 & $0.633-1.138$ \\
Education & -0.918 & 0.091 & 100.919 & 1 & 0.000 & 0.399 & $0.334-0.478$ \\
Constant & -0.491 & 0.358 & 1.882 & 1 & 0.170 & 0.612 & \\
\hline
\end{tabular}

\section{2). Obesity}

After adjusting for age and other factors of the SES, the factors of age, income, occupation, marital and education are of impact on obesity in the overall population. The higher occupation and income increase the risk of suffering from obesity, the lower education increases the risk of abdominal obesity and the single are more likely to suffer from obesity. (Table 6)

Table 6. Odds ratios of obesity adjusted for all socio-demographic characteristics in the overall population

\begin{tabular}{llllllll}
\hline & $\mathrm{B}$ & S.E, & Wals & df & Sig. & OR & OR95\%CI \\
\hline Age & -0.238 & 0.023 & 110.594 & 1 & 0.000 & 0.789 & $0.754-0.824$ \\
Income & 0.013 & 0.033 & 0.148 & 1 & 0.701 & 1.013 & $0.949-1.081$ \\
Occupation & 0.163 & 0.051 & 10.336 & 1 & 0.001 & 1.177 & $1.066-1.300$ \\
Marriage & -0.655 & 0.065 & 101.227 & 1 & 0.000 & 0.519 & $0.457-0.590$ \\
Education & -0.302 & 0.036 & 70.452 & 1 & 0.000 & 0.740 & $0.689-0.794$ \\
Constant & 0.779 & 0.156 & 24.805 & 1 & 0.000 & 2.179 & \\
\hline
\end{tabular}

After adjusting for age and other factors of the SES, income, occupation, marital status and education are of 
statistical impact in the male population and the lower level of education and income increase the risk of obesity and the higher occupational rank and the male single is more likely to suffer obesity. (Table 7)

Table 7. Odds ratios of obesity adjusted for all socio-demographic characteristics in the male population

\begin{tabular}{llllllll}
\hline & B & S.E, & Wals & df & Sig. & OR & OR95\%CI \\
\hline age & -0.063 & 0.030 & 4.529 & 1 & 0.323 & 0.939 & $0.886-0.995$ \\
income & -0.139 & 0.043 & 10.594 & 1 & 0.001 & 0.870 & $0.800-0.946$ \\
occupation & 0.298 & 0.069 & 18.552 & 1 & 0.000 & 1.347 & $1.176-1.542$ \\
marriage & -0.473 & 0.082 & 33.032 & 1 & 0.000 & 0.623 & $0.530-0.732$ \\
education & -0.073 & 0.044 & 2.743 & 1 & 0.098 & 0.930 & $0.853-1.013$ \\
constant & 0.168 & 0.216 & 0.602 & 1 & 0.438 & 1.183 & \\
\hline
\end{tabular}

After adjusting for age and other factors of the SES, occupation, education and marital status are of statistical impact in the female population, and the lower level of education and the higher occupational rank and income increase the risk of obesity and the female single is more likely to suffer from obesity. (Table 8)

Table 8 . Odds ratios of obesity adjusted for all socio-demographic characteristics in the female population

\begin{tabular}{llllllll}
\hline & B & S.E, & Wals & df & Sig. & OR & OR95\%CI \\
\hline age & -0.435 & 0.038 & 132.582 & 1 & 0.000 & 0.647 & $0.601-0.697$ \\
income & 0.299 & 0.058 & 26.920 & 1 & 0.000 & 1.349 & $1.205-1.551$ \\
occupation & 0.381 & 0.085 & 20.142 & 1 & 0.000 & 1.464 & $1.240-1.729$ \\
marriage & -0.939 & 0.120 & 61.002 & 1 & 0.000 & 0.391 & $0.309-0.495$ \\
education & -0.200 & 0.102 & 3.839 & 1 & 0.000 & 0.532 & $0.465-0.608$ \\
constant & 1.138 & 0.258 & 19.517 & 1 & 0.000 & 3.122 & \\
\hline
\end{tabular}

\section{3). Daily Alcohol Intake}

After adjusting for age and other factors of the SES, the factors of age, income, occupation, marital and education are of impact on the daily alcohol intake in the overall population. The lower education and less income increase the risk of suffering from the daily alcohol intake, the higher rank of occupation increases the risk of the daily alcohol intake and the married is more likely to suffer from the daily alcohol intake. (Table 9)

Table 9. Odds ratios of daily alcohol intake adjusted for all socio-demographic characteristics in the overall population

\begin{tabular}{llllllll}
\hline & $\mathrm{B}$ & $\mathrm{S} . \mathrm{E}$, & Wals & df & Sig. & OR & OR95\%CI \\
\hline Age & -0.357 & 0.041 & 74.593 & 1 & 0.000 & 0.700 & $0.654-0.759$ \\
Income & -0.346 & 0.055 & 40.329 & 1 & 0.000 & 0.707 & $0.636-0.787$ \\
Occupation & 1.281 & 0.117 & 120.137 & 1 & 0.000 & 3.600 & $2.863-4.527$ \\
Marriage & 0.554 & 0.103 & 29.056 & 1 & 0.000 & 1.740 & $1.422-2.127$ \\
Education & -1.285 & 0.071 & 330.472 & 1 & 0.000 & 0.277 & $0.241-0.318$ \\
Constant & -4.250 & 0.307 & 191.777 & 1 & 0.000 & 0.014 & \\
\hline
\end{tabular}

After adjusting for age and other factors of the SES, the factors of age, occupation, education and marital status are of impact on the daily alcohol intake in the male population. The lower education and less income increase the risk of suffering from the daily alcohol intake, the higher rank of occupation increases the risk of the daily alcohol 
intake and the single is more likely to suffer from the daily alcohol intake. (Table 10)

Table 10. Odds ratios of daily alcohol intake adjusted for all socio-demographic characteristics in the male population

\begin{tabular}{llllllll}
\hline & $\mathrm{B}$ & S.E, & Wals & $\mathrm{df}$ & Sig. & OR & OR95\%CI \\
\hline Age & -0.271 & 0.043 & 39.926 & 1 & 0.000 & 0.763 & $0.701-0.830$ \\
Income & -0.204 & 0.056 & 13.257 & 1 & 0.000 & 0.815 & $0.730-0.910$ \\
Occupation & 1.237 & 0.120 & 106.380 & 1 & 0.000 & 3.455 & $2.723-4.358$ \\
Marriage & 0.408 & 0.105 & 15.148 & 1 & 0.000 & 1.504 & $1.327-1.689$ \\
Education & -1.075 & 0.070 & 237.514 & 1 & 0.000 & 0.341 & $0.298-0.391$ \\
Constant & -3.492 & 0.310 & 127.194 & 1 & 0.000 & 0.030 & \\
\hline
\end{tabular}

After adjusting for age and other factors of the SES, the factors of age, occupation, education and marital status are of no statistical impact on the daily alcohol intake in the female population. (Table 11)

Table 11. Odds ratios of daily alcohol intake adjusted for all socio-demographic characteristics in the female population

\begin{tabular}{llllllll}
\hline & $\mathrm{B}$ & S.E, & Wals & df & Sig. & OR & OR95\%CI \\
\hline Age & -6.372 & 265.194 & 0.001 & 1 & 0.981 & 0.002 & - \\
Income & -26.131 & 1152.444 & 0.001 & 1 & 0.982 & 0.000 & - \\
Occupation & 12.255 & 1823.938 & 0.000 & 1 & 0.995 & 209973.407 & - \\
Marriage & 11.413 & 1200.743 & 0.000 & 1 & 0.992 & 90489.802 & - \\
Education & -22.388 & 579.435 & 0.001 & 1 & 0.969 & 0.000 & - \\
Constant & -9.816 & 7192.356 & 0.000 & 1 & 0.999 & 0.000 & \\
\hline
\end{tabular}

\section{4). Duration of drinking}

After adjusting for age and other factors of the SES, the factors of age, income, occupation, marital status and education are of impact on duration of drinking in the overall population. The higher rank of occupation and the lower education and the income increase the risk of suffering from duration of drinking, the single is more likely to suffer from duration of drinking. (Table 12)

Table 12. Odds ratios of duration of drinking adjusted for all socio-demographic characteristics in the overall population

\begin{tabular}{llllllll}
\hline & $\mathrm{B}$ & $\mathrm{S} . \mathrm{E}$, & Wals & df & Sig. & OR & OR95\%CI \\
\hline Age & -0.288 & 0.042 & 46.284 & 1 & 0.000 & 0.750 & $0.690-0.814$ \\
Income & -0.277 & 0.072 & 14.904 & 1 & 0.000 & 0.758 & $0.659-0.872$ \\
Occupation & 0.811 & 0.105 & 59.982 & 1 & 0.000 & 2.249 & $1.832-2.761$ \\
Marriage & -1.562 & 0.134 & 135.815 & 1 & 0.000 & 0.210 & $0.161-0.273$ \\
Education & -1.062 & 0.081 & 170.495 & 1 & 0.000 & 0.346 & $0.295-0.406$ \\
Constant & -0.049 & 0.315 & 0.025 & 1 & 0.875 & 0.952 & \\
\hline
\end{tabular}

After adjusting for age and other factors of the SES, the factors of age, income, occupation, marital status and education are of impact on the duration of drinking in the overall population. The higher rank of occupation and the lower education and the income increase the risk of suffering from duration of drinking, the single is more likely to 
suffer from duration of drinking. (Table 13)

Table 13. Odds ratios of duration of drinking adjusted for all socio-demographic characteristics in the male population

\begin{tabular}{llllllll}
\hline & $\mathrm{B}$ & S.E, & Wals & df & Sig. & OR & OR95\%CI \\
\hline Age & -0.182 & 0.051 & 12.646 & 1 & 0.000 & 0.833 & $0.754-0.921$ \\
Income & -0.225 & 0.086 & 6.797 & 1 & 0.000 & 0.798 & $0.674-0.946$ \\
Occupation & 1.074 & 0.139 & 59.919 & 1 & 0.000 & 2.927 & $2.230-3.841$ \\
Marriage & -1.745 & 0.151 & 132.807 & 1 & 0.000 & 0.175 & $0.130-0.235$ \\
Education & -1.064 & 0.096 & 123.110 & 1 & 0.000 & 0.345 & $0.286-0.416$ \\
Constant & 0.426 & 0.402 & 1.121 & 1 & 0.290 & 1.531 & \\
\hline
\end{tabular}

After adjusting for age and other factors of the SES, the factors of age, occupation, education and marital status are of impact on duration of drinking in the female population. The higher level of education and the lower occucation and the income increase the risk of suffering from duration of drinking, the single is more likely to suffer from duration of drinking. (Table 14)

Table 14. Odds ratios of duration of drinking adjusted for all socio-demographic characteristics in the female population

\begin{tabular}{llllllll}
\hline & $\mathrm{B}$ & S.E, & Wals & df & Sig. & OR & OR95\%CI \\
\hline Age & -1.185 & 0.140 & 71.895 & 1 & 0.000 & 0.306 & $0.233-0.402$ \\
Income & -1.338 & 0.209 & 40.874 & 1 & 0.000 & 0.262 & $0.174-0.395$ \\
Occupation & -0.281 & 0.249 & 1.277 & 1 & 0.258 & 0.755 & $0.464-1.229$ \\
Marriage & -1.378 & 0.317 & 18.876 & 1 & 0.000 & 0.252 & $0.135-0.469$ \\
Education & 0.467 & 0.193 & 5.844 & 1 & 0.016 & 1.595 & $1.092-2.330$ \\
Constant & 1.932 & 0.796 & 5.892 & 1 & 0.015 & 6.905 & \\
\hline
\end{tabular}

\section{5). HBV infection}

After adjusting for age and other factors of the SES, the factors of age, income, occupation and marital status are of impact on HBV infection in the overall population. The increasing age, the lower education and the higher rank of occupation increase the risk of suffering from HBV infection, the single is more likely to suffer from HBV infection. (Table 15)

Table 15. Odds ratios of HBV infection adjusted for all socio-demographic characteristics HBV infection in the overall population

\begin{tabular}{llllllll}
\hline & B & S.E, & Wals & df & Sig. & OR & OR95\%CI \\
\hline age & 0.165 & 0.050 & 11.135 & 1 & 0.001 & 1.180 & $1.071-1.300$ \\
income & -0.054 & 0.067 & 0.642 & 1 & 0.423 & 0.948 & $0.831-1.081$ \\
occupation & 0.799 & 0.122 & 42.645 & 1 & 0.000 & 2.223 & $1.749-2.826$ \\
marriage & -0.403 & 0.145 & 7.708 & 1 & 0.005 & 0.668 & $0.502-0.888$ \\
education & -0.189 & 0.084 & 5.009 & 1 & 0.025 & 0.828 & $0.701-0.977$ \\
constant & -4.275 & 0.345 & 153.911 & 1 & 0.000 & 0.014 & \\
\hline
\end{tabular}

After adjusting for age and other factors of the SES, the factors of age, income, marital status and occupation are of 
impact on HBV infection in the male population. The increasing age and the lower education increase the risk of suffering from HBV infection, the single is more likely to suffer from HBV infection. (Table 16)

Table 16. Odds ratios of HBV infection adjusted for all socio-demographic characteristics HBV infection in the male population

\begin{tabular}{llllllll}
\hline & B & S.E, & Wals & df & Sig. & OR & OR95\%CI \\
\hline age & 0.281 & 0.068 & 17.205 & 1 & 0.000 & 1.325 & $1.160-1.513$ \\
income & -0.154 & 0.090 & 2.928 & 1 & 0.087 & 0.857 & $0.718-1.023$ \\
occupation & -0.025 & 0.163 & 0.024 & 1 & 0.877 & 0.975 & $0.708-1.343$ \\
marriage & -1.999 & 0.293 & 46.451 & 1 & 0.000 & 0.136 & $0.076-0.241$ \\
education & -0.032 & 0.101 & 0.098 & 1 & 0.754 & 0.969 & $0.794-1.182$ \\
constant & -0.673 & 0.518 & 1.692 & 1 & 0.193 & 0.510 & \\
\hline
\end{tabular}

After adjusting for age and other factors of the SES, the factors of age, marital status and occupation are of impact on HBV infection in the female population. The lower education and the higher level income and higher rank of occupation increase the risk of suffering from HBV infection, the married is more likely to suffer from HBV infection. (Table 17)

Table 17. Odds ratios of HBV infection adjusted for all socio-demographic characteristics HBV infection in the female population

\begin{tabular}{llllllll}
\hline & B & S.E, & Wals & df & Sig. & OR & OR95\%CI \\
\hline age & 0.030 & 0.081 & 0.141 & 1 & 0.709 & 1.031 & $0.879-1.209$ \\
income & 0.283 & 0.121 & 5.491 & 1 & 0.019 & 1.327 & $1.047-1.681$ \\
occupation & 2.124 & 0.227 & 87.543 & 1 & 0.000 & 8.363 & $5.360-13.049$ \\
marriage & 0.979 & 0.210 & 21.701 & 1 & 0.000 & 2.662 & $1.763-4.019$ \\
education & -0.663 & 0.163 & 16.540 & 1 & 0.000 & 0.516 & $0.375-0.709$ \\
constant & -8.702 & 0.613 & 201.647 & 1 & 0.000 & 0.000 & \\
\hline
\end{tabular}

\section{Regression logistic analysis of the socio-economic conditions and the risk factors of alcoholic liver disease}

In male population, the risk of obesity and abdominal obesity were highest in the 50- to 59-year-old group. The risk of obesity and abdominal obesity were lowest in highest educated and highest level of family income but highest in higher rank of occupation individuals. Being currently unmarried was a risk factor for obesity and abdominal obesity in male population. The risk of daily alcohol intake was highest in the 30- to 39-year-old group. The risk of daily alcohol intake was higher in higher educated and higher level of family income but highest in lowest rank of occupation individuals. Being currently married was a risk factor for daily alcohol intake in male population. The risk of duration of drinking was highest in the 18- to 29-year-old group. The risk of duration of drinking was higher in higher educated and higher level of family income but highest in lowest rank of occupation individuals. Being currently unmarried was a risk factor for duration of drinking in male population. The risk of HBV infection was highest in the oldest age group. The risk of HBV infection was higher in higher educated and higher level of family income but highest in lowest rank of occupation individuals. Being currently unmarried was a risk factor for HBV infection in male population (Table 18). 
Table 18. Regression logistic analysis of the socio-economic conditions and the risk factors of alcoholic liver disease in the male population

\begin{tabular}{|c|c|c|c|c|c|}
\hline \multirow{3}{*}{ Predictors } & obesity & abdominal obesity & daily alcohol intake & duration of drinking & HBV infection \\
\hline & OR & OR & OR & OR & OR \\
\hline & OR95\%CI & OR95\%CI & OR95\%CI & OR95\%CI) & OR95\%CI \\
\hline \multicolumn{6}{|l|}{ Age, in years } \\
\hline \multirow{2}{*}{$18-29$} & $1.367^{\mathrm{a}}$ & 1.109 & $1.759^{\mathrm{a}}$ & $15.541^{\mathrm{a}}$ & $0.390^{\mathrm{a}}$ \\
\hline & $1.044-1.790$ & $0.781-1.328$ & $1.179-2.624$ & $8.945-27.001$ & $0.246-0.618$ \\
\hline \multirow{2}{*}{$30-39$} & 1.128 & 1.160 & $5.382^{\mathrm{a}}$ & $10.299^{\mathrm{a}}$ & $0.208^{\mathrm{a}}$ \\
\hline & $0.858-1.482$ & $0.886-1.518$ & $3.653-7.930$ & $5.934-17.875$ & $0.125-0.347$ \\
\hline \multirow{2}{*}{$40-49$} & 0.821 & $1.556^{\mathrm{a}}$ & 0.948 & $8.960^{\mathrm{a}}$ & $0.195^{\mathrm{a}}$ \\
\hline & $0.624-1.080$ & $1.197-2.022$ & $0.631-1.423$ & $5.531-14.515$ & $0.117-0.323$ \\
\hline \multirow{2}{*}{$50-59$} & $1.652^{\mathrm{a}}$ & $2.436^{\mathrm{a}}$ & $3.591^{\mathrm{a}}$ & $3.083^{\mathrm{a}}$ & $0.531^{\mathrm{a}}$ \\
\hline & $1.215-2.246$ & $1.795-3.303$ & $2.581-6.049$ & $2.581-6.049$ & $0.298-0.948$ \\
\hline $60-$ & $1.00(\operatorname{Ref})$ & $1.00(\mathrm{Ref})$ & $1.00($ Ref $)$ & $1.00(\mathrm{Ref})$ & $1.00(\operatorname{Ref})$ \\
\hline \multicolumn{6}{|c|}{ Years of education } \\
\hline$<7$ & $1.00(\operatorname{Ref})$ & $1.00($ Ref) & $1.00(\operatorname{Ref})$ & $1.00($ Ref $)$ & $1.00(\operatorname{Ref})$ \\
\hline \multirow{2}{*}{ 7-9 } & 0.360 & $0.554^{\mathrm{a}}$ & $12.203^{\mathrm{a}}$ & $9.839^{\mathrm{a}}$ & 1.318 \\
\hline & $0.283-0.458$ & $0.439-0.700$ & $8.701-17.115$ & $5.903-16.401$ & $0.807-2.513$ \\
\hline \multirow{2}{*}{$>9$} & 0.704 & $1.343^{\mathrm{a}}$ & $1.672^{\mathrm{a}}$ & $2.102^{\mathrm{a}}$ & $1.688^{*}$ \\
\hline & $0.565-0.877$ & $1.167-1.784$ & $1.189-2.353$ & $1.335-3.309$ & $1.083-2.630$ \\
\hline \multicolumn{6}{|c|}{ Mean monthly per capia family income, RMB } \\
\hline $0-$ & $1.00(\operatorname{Ref})$ & $1.00(\operatorname{Ref})$ & $1.00(\operatorname{Ref})$ & $1.00($ Ref $)$ & $1.00(\operatorname{Ref})$ \\
\hline \multirow{2}{*}{ 800- } & $0.527^{\mathrm{a}}$ & 1.194 & 1.243 & 1.235 & 1.392 \\
\hline & $0.438-0.635$ & $0.999-1.428$ & $0.981-1.575$ & $0.831-1.837$ & $0.967-2.004$ \\
\hline \multirow{2}{*}{$1600-$} & $0.789^{\mathrm{a}}$ & $1.578^{* *}$ & 0.772 & $0.607^{*}$ & 0.829 \\
\hline & $0.647-0.961$ & $1.299-1.916$ & $0.593-1.006$ & $0.409-0.992$ & $0.537-1.280$ \\
\hline \multicolumn{6}{|l|}{ Occupation } \\
\hline unemployed & 1.00 (Ref) & $1.00($ Ref) & 1.00 (Ref) & 1.00 (Ref) & 1.00 (Ref) \\
\hline \multirow{2}{*}{ blue collar } & $0.558^{\mathrm{a}}$ & $0.2^{\mathrm{a}}$ & $0.250^{\mathrm{a}}$ & $0.463^{\mathrm{a}}$ & 0.732 \\
\hline & $0.394-0.790$ & $0.141-0.284$ & $0.149-0.417$ & $0.231-0.928$ & $0.359-1.493$ \\
\hline \multirow{2}{*}{ white collar } & $2.662^{\mathrm{a}}$ & 1.265 & $0.304^{\mathrm{a}}$ & 0.832 & 0.695 \\
\hline & $2.081-3.406$ & $0.998-1.603$ & $0.216-0.429$ & $0.435-1.590$ & $0.426-1.135$ \\
\hline \multicolumn{6}{|l|}{ Marital status } \\
\hline married & $1.00($ Ref) & $1.00(\operatorname{Ref})$ & $1.00(\operatorname{Ref})$ & $1.00($ Ref $)$ & $1.00($ Ref $)$ \\
\hline \multirow{2}{*}{ unmarried } & $1.767^{\mathrm{a}}$ & $1.414^{\mathrm{a}}$ & $0.518^{\mathrm{a}}$ & $2.933^{\mathrm{a}}$ & $10.578^{\mathrm{a}}$ \\
\hline & $1.456-2.145$ & $1.181-1.693$ & $0.410-0.655$ & $2.070-4.155$ & $5.735-19.511$ \\
\hline
\end{tabular}

${ }^{\mathrm{a}}$ Odds ratio is significant, $\mathrm{p}<0.05$.

${ }^{\mathrm{b}}$ Adjusted for age, education, income, occupation, marital, HBV infection, causes of alcohol, types of alcohol beverage, daily alcohol intake, duration of drinking, body mass index and waist circumference.

Ref, reference category.

In female population, the risk of obesity and abdominal obesity were highest in lowest level of family income and lowest rank of occupation individuals but higher in higher educated. Being currently unmarried was a risk factor for obesity and abdominal obesity in female population. There were no statistical significance in terms of the risk of daily alcohol intake, duration of drinking and HBV infection because of lower prevalence of ALD in female 
population. (Table 19)

Table 19. Logistic analysis of the socio-economic conditions and the risk factors of alcoholic liver disease in the female population

\begin{tabular}{|c|c|c|c|c|c|}
\hline \multirow{3}{*}{ Predictors } & obesity & abdominal obesity & daily alcohol intake & duration of drinking & HBV infection \\
\hline & OR & OR & OR & OR & OR \\
\hline & OR95\%CI & OR95\%CI & OR95\%CI & OR95\%CI) & OR95\%CI \\
\hline \multicolumn{6}{|l|}{ Age, in years } \\
\hline \multirow{2}{*}{$18-29$} & $8.272 \mathrm{E} 7$ & $2.60 \mathrm{E} 8$ & $7.733 \mathrm{E} 11$ & $4.810 \mathrm{E} 6$ & $0.149^{\mathrm{a}}$ \\
\hline & 0 & 0 & 0 & 0 & $0.088-0.253$ \\
\hline \multirow{2}{*}{$30-39$} & $1.661 \mathrm{E} 8$ & $6.275 \mathrm{E} 8$ & $1.661 \mathrm{E} 8$ & $7.810 \mathrm{E} 30$ & $0.208^{\mathrm{a}}$ \\
\hline & 0 & 0 & 0 & 0 & 0 \\
\hline \multirow{2}{*}{$40-49$} & $4.703 \mathrm{E} 7$ & $1.511 \mathrm{E} 8$ & $4.703 \mathrm{E} 7$ & $4.1493 \mathrm{E} 27$ & $0.195^{\mathrm{a}}$ \\
\hline & 0 & 0 & 0 & 0 & 0. \\
\hline \multirow{2}{*}{$50-59$} & $4.224 \mathrm{E} 8$ & $7.034 \mathrm{E} 8$ & $4.224 \mathrm{E} 8$ & $1.739 \mathrm{E} 25$ & 1.131 \\
\hline & 0 & 0 & 0 & 0 & $0.338-3.785$ \\
\hline $60-$ & $1.00($ Ref $)$ & $1.00($ Ref $)$ & 1.00 (Ref) & $1.00($ Ref $)$ & $1.00(\operatorname{Ref})$ \\
\hline \multicolumn{6}{|c|}{ Years of education } \\
\hline$<7$ & 1.00 (Ref) & 1.00 (Ref) & $1.00(\operatorname{Ref})$ & $1.00(\operatorname{Ref})$ & 1.00 (Ref) \\
\hline \multirow{2}{*}{ 7-9 } & $18.927^{\mathrm{a}}$ & $5.036^{\mathrm{a}}$ & $9.114 \mathrm{E} 14$ & 0.010 & 2.472 \\
\hline & $11.698-30.622$ & $3.618-7.009$ & 0 & 0 & $0.724-8.437$ \\
\hline \multirow{2}{*}{$>9$} & $0.704^{\mathrm{a}}$ & 0.848 & $1.255 \mathrm{E} 8$ & $1.313 \mathrm{E} 5$ & 0 \\
\hline & $5.155-12.181$ & $0.616-1.168$ & 0 & 0 & 0 \\
\hline \multicolumn{6}{|c|}{ Mean monthly per capia family income, RMB } \\
\hline $0-$ & 1.00 (Ref) & 1.00 (Ref) & $1.00(\operatorname{Ref})$ & $1.00(\operatorname{Ref})$ & 1.00 (Ref) \\
\hline \multirow{2}{*}{ 800- } & $0.182^{\mathrm{a}}$ & 0.812 & $5.803 \mathrm{E} 5$ & $8.052 \mathrm{E} 7$ & 0.477 \\
\hline & $0.130-0.255$ & $0.636-1.037$ & 0 & 0 & $0.266-0.854$ \\
\hline \multirow{2}{*}{$1600-$} & $0.297^{\mathrm{a}}$ & 1.010 & 4.604 & $1.422 \mathrm{E} 14$ & 0 \\
\hline & $0.213-0.414$ & $0.782-1.304$ & 0 & 0 & 0 \\
\hline \multicolumn{6}{|l|}{ Occupation } \\
\hline unemployed & $1.00(\operatorname{Ref})$ & $1.00(\operatorname{Ref})$ & $1.00(\operatorname{Ref})$ & $1.00(\operatorname{Ref})$ & $1.00(\operatorname{Ref})$ \\
\hline \multirow{2}{*}{ blue collar } & 0.874 & 0.770 & 0.002 & 2640.514 & 0 \\
\hline & $0.542-1.408$ & $0.513-1.156$ & 0 & 0 & 0 \\
\hline \multirow{2}{*}{ white collar } & $0.369^{\mathrm{a}}$ & $0.477^{\mathrm{a}}$ & 0 & $3.172 \mathrm{E} 5$ & $0.065^{\mathrm{a}}$ \\
\hline & $0.240-0.568$ & $0.342-0.666$ & 0 & 0 & $0.035-0.124$ \\
\hline \multicolumn{6}{|l|}{ Marital status } \\
\hline married & 1.00 (Ref) & 1.00 (Ref) & $1.00(\operatorname{Ref})$ & $1.00(\operatorname{Ref})$ & 1.00 (Ref) \\
\hline \multirow{2}{*}{ unmarried } & 1.108 & $2.247^{\mathrm{a}}$ & 0 & 215.56 & $0.358^{\mathrm{a}}$ \\
\hline & $0.799-1.537$ & $1.700-2.968$ & 0 & 0 & $0.202-0.634$ \\
\hline
\end{tabular}

${ }^{\mathrm{a} O d d s}$ ratio is significant, $\mathrm{p}<0.05$.

${ }^{\mathrm{b}}$ Adjusted for age, education, income, occupation, marital, HBV infection, causes of alcohol, types of alcohol beverage, daily alcohol intake, duration of drinking, body mass index and waist circumference.

Ref, reference category. 


\section{Discussion}

\section{(A) The survey sample}

The survey was carried out in Taishan district in Tai'an city and 15 neighborhood communities and 7295 respondents were randomly selected. Taishan district is one of the small and medium-sized cities in northern China The results of this survey can reflect the relationship between the socio-economic situation of north China residents with alcoholic liver disease risk factors.

(B) The results of the survey

\section{1). Alcoholic liver disease prevalence}

The survey shows that the prevalence of ALD is $8.55 \%$ (male $15.76 \%$, VS female $1.42 \%, p<0.05$ ) and higher than some domestic epidemiological investigations (Li et al., 2003; Lu et al., 2003; Yan et al., 2007; Huang et al., 2005; Fan et al., 2005; Sun, 2008; Zhou et al., 2007). This result may be related to the following factors. Firstly, Shandong Province is in northern China, because of the customs of booze alcoholic liver disease is of a higher prevalence in the South (Cochrane et al., 2003). Secondly, people in the north who are fat are more likely to suffer from nonalcoholic fatty liver than other populations, the study didn't do liver biopsy, so the non-alcoholic fatty liver which can not be identified is regarded as alcoholic liver disease according to alcohol consumption. Thirdly, in recent years, the production and consumption of alcohol in China increased as a result of the rapid social and economic changes (Hao et al., 2004; Kim et al., 2008; Zhou et al., 2009). Previously reported prevalence of ALD were out of date, which do not represent population data.

\section{2). Gender}

The proportion of alcoholic liver disease of male drinking population is far greater than the female, and the low prevalence of female alcoholic liver disease, similar to the results of other studies (Hao et al., 1999; Shi et al., 2005). The analysis of SES factors and alcoholic liver disease risk is of a certain bias in the female population, so the study in the male population, to some extent, can be on behalf of the overall population. The reasons are as the following: first, the females who need commitment within the most domestic activities and enjoy less social activities than the male have less drinking opportunities and generally do not be insisted on drinking in social situations unless on their own initiative. Second, influenced by traditional machismo culture, the females are not wanted to take part in some social activities and thus are limited to drink. Third, the females have a strong sense of self-protection because of traditional education and thus, to some extent, limit alcohol intake (Li et al., 2012). Fourth, the females have the fertile responsibility and it is believed that alcohol is not conducive to the healthy growth of the next generation.

\section{3). HBV infection}

Among 7295 interviewees the number of hepatitis b is 367 people, accounting for $5.03 \%$ of the total interviewees, among 6671 healthy individuals the number of hepatitis $\mathrm{b}$ is 328 , accounting for $4.9 \%$ of the healthy individuals; among 624 ALD individuals the number of hepatitis $\mathrm{b}$ is 39 , accounting for $6.3 \%$ of the total number of ALD. There was no prevalent difference between healthy individuals and ALD individuals (the HBV infection prevalence rate of $4.9 \%$ vs $6.3 \%, \mathrm{p}>0.05$ ), which meets with national coverage ( $\mathrm{Li}$ et al., 2003; Lu et al., 2003; Huang et al., 2003; Cui et al., 2010). In the present study, due to the small number of hepatitis b, there should be more discussion about relationship between hepatitis $b$ and alcohol. Hepatitis B virus infected people are mostly in maternal and child communicators, there is very little chance of drinking in this part of the population, thus the alcoholic liver disease risk factors are of significance in further study. This may be due to the fact that among the study population those with HBV infections through mother-child transmission are in the majority. This group of people with chronic hepatitis $b$ are consciously away from alcohol for the fear of prognosis. Accordingly, in China the significance of regarding HBV infection as a risk for ALD needs further examination and research.

(C) The results of this study (take the male population as an example)

Our study has found that people with the higher level careers are at a higher risk of getting obesity and abdominal obesity, that those with low-level careers are more likely to be addicted to daily consumption of alcohol or longer years of drinking alcohol. The former may result from the fact that these people are mental workers, with a steady job and a merry mood, and lack enough amount of outdoor exercise; the latter can be emphasized by the fact that they are manual workers believing that moderate alcohol or high spirits can help people recover from fatigue.

The study has also revealed that male singles are at a higher risk of getting obesity, abdominal obesity and longer years of drinking alcohol, whereas married men have a higher daily consumption of alcohol. The reasons for this may be as follows: Firstly, singles do not live regular life and always make a pig of themselves. Secondly, they are 
under much pressure from society and more subjected to anxiety and depression. In addition, male singles have lower economic status and fewer social activities compared with married men.

In the meantime, low literacy contributes a lot to overweight and obesity. This may be explained by the fact that people with lower literacy don't know much about how to balance their diets or obtain adequate nutrition, that they have fewer lines of acquiring the knowledge of elderly care.

What's more, the increased monthly family income is the lead risk for overweight and obesity. This is because people's excessive intake of animal food energy, protein and fat exceeds physical requirements. Still, educational level and monthly family average income is in proportion to the risk of daily consumption of alcohol and years of drinking alcohol. This is where Chinese traditions enter. People have long believed that drinking in social gatherings is part of work and life. It is true that people with more education are white collars and the host of kinds of social activities. It is also true that this belief undoubtedly has produced many alcohol-related diseases such as overweight and obesity among this group of people.

\section{Acknowledgements}

This project was supported by Taishan District Health Bureau in Tai'an City.We are grateful to Dr Ning Fu(Taishan University,China)for her linguistic guidance on the manuscipt.

\section{Competing Interests Statement}

The authors declare that there are no competing or potential conflicts of interest.

\section{References}

Anuurad, E., Shiwaku, K., Nogi, A., Kitajima, K., Enkhmaa, B., Shimono, K., \& Yamane, Y. (2003). The new BMI criteria for Asians by the regional office for the western pacific region of WHO are suitablefor screening of overweight to prevent metabolic syndrome in elder Japanese workers. J Occup Health, 45, 335-343. https://doi.org/10.1539/joh.45.335

Centers for Disease Control and Prevention. (2009). Sociodemographic differences in binge drinking among adults-14 states, 2004. Morbidity and Mortality Weekly Report, 58, 310-304. https://doi.org/10.1093/humrep/17.10.2552

Chinese Nutrition Society. (2008). China's Dietary Guidelines (2007). Lhasa: Tibet people's publishing house: 90-95. [in Chinese]

Cochrane, J., Chen, H., Conigrave, K. M., \& Hao, W. (2003). Alcohol use in China. Alcohol Alcohol, 38, 537-542. https://doi.org/10.1093/alcalc/agg111

Cooperative group of alcoholic liver disease. (2007). A multicenter study of alcoholic liver disease in China. Chin $J$ Dig, 27, 231-234. [in Chinese]

Employment Statistics National Bureau of Statistics of the People's Republic of China. (2011) Tabulation on the 2010 Population Censue of the People's Republic of China. Beijing: China statistics press. [in Chinese].

Fan, J. G., Zhu, J., Li, X. J., Li, R., Dai, F., Song, X. M., Liu, T. S., Li, F., \& Chen, S. Y. (2005). Epidemiologically survey on relation of fatty liver with alcohol drinking and obesity. Chinese Hepatology, 10, 179-181. [in Chinese]

Fatty liver and alcoholic liver disease study group of the Chinese liver disease association. (2010). Guidelines for diagnosis and treatment alcohol liver disease. Chin J Hepatol, 3, 164-168. [in Chinese]

Hao, W., Su, Z., Liu, B., Zhang, K., Yang, H., Chen, S., Biao, M., \& Cui, C. (2004). Drinking and drinking patterns and health status in the general population of five areas of China. Alcohol Alcohol, 39, 43-52. https://doi.org/10.1021/cg8006525

Hao, W., Young, D. S., Xiao, S. Y., Li, L. J., \& Zhang, Y. L. (1999). Alcohol consumption and alcohol-related problems:Chinese experience from six area samples, 1994. Addiction, 94, 1467-1476. https://doi.org/10.1046/j.1360-0443.1999.941014673.x

Huang, S. L., Dai, S. Q., Zang, X. H., Yu, Y. J., Tan, M. L., \& Yi, C. G. (2005) An epidemiological survey of alcoholic liver disease in Hunan Province. Chin J Physician, 7, 426- 427. [in Chinese]

Jepsen, P., Vilstrup, H., Andersen, P. K., \& Sørensen, H. T. (2009). Socioeconomic status and survival of cirrhosis patients: a Danish nationwide cohort study. BMC Gastroenterol, $18, \quad 9,35$. https://doi.org/10.1186/1471-230X-9-35 
Joint committee for developing Chinese guidelines on prevention and treatment of dyslipidemia in adults. (2007) Chinese guidelines on prevention and treatment of dyslipidemia in adults. Chin J Cardiol, 35, 390-415. [in Chinese]

Joint committee for developing Chinese guidelines on prevention and treatment of dyslipidemia in adults. (2007). Chinese guidelines on prevention and treatment of dyslipidemia in adults. Chin J Cardiol, 35, 390-415. [in Chinese]

Kim, J. H., Lee, S., Chow, J., Lau, J., Tsang, A., Choi, J., \& Griffiths, S. M. (2008). Prevalence and the factors associated with binge drinking, alcohol abuse, and alcohol dependence: a population-based study of Chinese adults in Hong Kong. Alcohol Alcohol, 43, 360-370. https://doi.org/10.1093/alcalc/agm181

Li, X., Li, S. J., Li, H., Ruan, D. C., Liu, Z. M., Jin, X. W., ... Li, Z. F. (2012). Investigation and analysis of drinking behavior of adult residents in some areas of Liaoning Province in 2009. Chin J Prev Contr Chron Dis, 20, 327-331. [in Chinese].

Li, Y. M., Chen, W. X., Yu, C. H., Yue, M., Liu, Y. S., Xu, G. Y., ... Li, S. D. (2003). An epidemiological survey of alcoholic liver disease in Zhejiang Province. Chin J Hepatol, 11, 647- 649. [in Chinese].

Lu, X. L., Tao, M., Luo, J. Y., Gen, Y., \& Zhao, H. L. (2003). Epidemiology of alcoholic liver disease in Xi'an. World Chin J Digestol, 11, 719-722. [in Chinese]

Massey, V. L., \& Arteel, G. E. (2012). Acute alcohol-induced liver injury. Front Physiol, 3, 193. https://doi.org/10.3389/fphys.2012.00193

Moghe, A., Joshi-Barve, S., Ghare, S., Gobejishvili, L., Kirpich, I., McClain, C. J., \& Barve, S. (2011) Histone modifications and alcohol-induced liver disease: are altered nutrients the missing link? World J Gastroenterol 17, 2465-2472. https://doi.org/10.3748/wjg.v17.i20.2465

Neild, B. (2013). World's 10 best drinking nations. Retrieved from http://edition.cnn.com/2013/03/15 /travel/best-drinking-nations.

Rasineni, K., \& Casey, C. A. (2012) Molecular mechanism of alcoholic fatty liver. Indian J Pharmacol, 44, 299-303. https://doi.org/10.4103/0253-7613.96297

Rehm, J. (2011). The risks associated with alcohol use and alcoholism. Alcohol Res Health, 34, 135-143.

Shi, Q. C., Zhang, J. M., Xu, F. Z., Fei, L. P., Xu, Y., Fu, Y. L., .. Yu, M. (2005). Epidemiological survey of mental illnesses in the people aged 15 and older in Zhejiang Province, China. Chin J Prev Med., 39, 229-236. [in Chinese]

Sun, J. (2008). The Status of Epidemiological Investigation and Analysis of Relevant Factors about Drinking and Alcoholic Liver Disease in DeHui City. Ph.D.diss ,Jilin University. [in Chinese].

Urban economic society of China small and medium-sized city's economic development commission. (2012). Annual Report on Development of Small and Medium-sized Cities inChina (2012). Beijing: Social sciences academic press. [in Chinese].

Wang, H. X., Ma, L. X., Yin, Q. L., Zhang, X. W., \& Zhang, X. W. (2014). Prevalence of Alcoholic Liver Disease and Its Association with Socioeconomic Status in North-Eastern China. Alcohol Clin Exp Res, 38, 1035-41. https://doi.org/10.1111/acer.12321

World Health Organization. (2007). Global alcohol database. Retrieved September 2, 2007, from www.who.int/global/dataquery

World Health Organization. (2011). Global status report on alcohol and health. Retrieved Februray 11, 2011, from www.who.int/globalatlas/alcohol

Yan, H., Lu, X. L., Luo, J. Y., \& Zhou, X. Y. (2007). Epidemiological analysis of alcoholic and non-alcoholic fatty liver in Shanxi and Gansu province. Chin J Gastroenterol Hepatol, 16, 347-350. [in Chinese]

Zhou, L., Conner, K. R., Phillips, M. R., Caine, E. D., Xiao, S., Zhang, R., \& Gong, Y. (2009). Epidemiology of alcohol abuse and dependence in rural Chinese men. Alcohol Clin Exp Res, 33, 1770-1776. https://doi.org/10.1111/j.1530-0277.2009.01014.x

Zhou, Y. J., Li, Y. Y., Nie, Y. Q., Ma, J. X., Lu, L. G., Shi, S. L., .. Hu, P. J. (2007). Prevalence of fatty liver disease and its risk factors in the population of South China. World J Gastroenterol, 13, 6419-6424. https://doi.org/10.3748/wjg.v13.i47.6419 


\section{Copyrights}

Copyright for this article is retained by the author(s), with first publication rights granted to the journal.

This is an open-access article distributed under the terms and conditions of the Creative Commons Attribution license (http://creativecommons.org/licenses/by/4.0/). 